Article

\title{
Investigate on the Mechanism of $\mathrm{HfO}_{2} / \mathrm{Si}_{0.7} \mathrm{Ge}_{0.3}$ Interface Passivation Based on Low-Temperature Ozone Oxidation and Si-Cap Methods
}

\author{
Qide Yao ${ }^{1,2} \oplus$, Xueli Ma ${ }^{2, *}$, Hanxiang Wang ${ }^{1,2}$, Yanrong Wang ${ }^{1, *}$, Guilei Wang ${ }^{2}{ }^{\circledR}$, Jing Zhang ${ }^{1}$, Wenkai Liu ${ }^{1}$, \\ Xiaolei Wang ${ }^{2}$, Jiang Yan ${ }^{1}$, Yongliang $\mathrm{Li}^{2, *}$ (i) and Wenwu Wang ${ }^{2}$ \\ 1 School of Information Science and Technology, North China University of Technology, Beijing 100144, China; \\ yaoqide@ime.ac.cn (Q.Y.); wanghanxiang@ime.ac.cn (H.W.); zhangj@ncut.edu.cn (J.Z.); \\ liuwk@ncut.edu.cn (W.L.); yanjiang@ncut.edu.cn (J.Y.) \\ 2 Integrated Circuit Advanced Process Center, Institute of Microelectronics, Chinese Academy of Science, \\ Beijing 100029, China; wangguilei@ime.ac.cn (G.W.); wangxiaolei@ime.ac.cn (X.W.); \\ wangwenwu@ime.ac.cn (W.W.) \\ * Correspondence: maxueli@ime.ac.cn (X.M.); wangyanrong@ncut.edu.cn (Y.W.); liyongliang@ime.ac.cn (Y.L.)
}

check for updates

Citation: Yao, Q.; Ma, X.; Wang, H.; Wang, Y.; Wang, G.; Zhang, J.; Liu, W.; Wang, X.; Yan, J.; Li, Y.; et al.

Investigate on the Mechanism of $\mathrm{HfO}_{2} / \mathrm{Si}_{0.7} \mathrm{Ge}_{0.3}$ Interface Passivation Based on Low-Temperature Ozone Oxidation and Si-Cap Methods. Nanomaterials 2021, 11, 955. https:// doi.org/10.3390/nano11040955

Academic Editor: Alexander Kromka

Received: 23 February 2021

Accepted: 7 April 2021

Published: 9 April 2021

Publisher's Note: MDPI stays neutral with regard to jurisdictional claims in published maps and institutional affiliations.

Copyright: (C) 2021 by the authors. Licensee MDPI, Basel, Switzerland. This article is an open access article distributed under the terms and conditions of the Creative Commons Attribution (CC BY) license (https:/ / creativecommons.org/licenses/by/ $4.0 /)$.

\begin{abstract}
The interface passivation of the $\mathrm{HfO}_{2} / \mathrm{Si}_{0.7} \mathrm{Ge}_{0.3}$ stack is systematically investigated based on low-temperature ozone oxidation and Si-cap methods. Compared with the $\mathrm{Al}_{2} \mathrm{O}_{3} / \mathrm{Si}_{0.7} \mathrm{Ge}_{0.3}$ stack, the dispersive feature and interface state density $\left(\mathrm{D}_{\text {it }}\right)$ of the $\mathrm{HfO}_{2} / \mathrm{Si}_{0.7} \mathrm{Ge}_{0.3}$ stack MOS (Metal-OxideSemiconductor) capacitor under ozone direct oxidation (pre-O sample) increases obviously. This is because the tiny amounts of $\mathrm{GeO}_{\mathrm{x}}$ in the formed interlayer (IL) oxide layer are more likely to diffuse into $\mathrm{HfO}_{2}$ and cause the $\mathrm{HfO}_{2} / \mathrm{Si}_{0.7} \mathrm{Ge}_{0.3}$ interface to deteriorate. Moreover, a post- $\mathrm{HfO}_{2}$-deposition (post-O) ozone indirect oxidation is proposed for the $\mathrm{HfO}_{2} / \mathrm{Si}_{0.7} \mathrm{Ge}_{0.3}$ stack; it is found that compared with pre-O sample, the $\mathrm{D}_{i t}$ of the post-O sample decreases by about $50 \%$ due to less $\mathrm{GeO}_{\mathrm{x}}$ available in the IL layer. This is because the amount of oxygen atoms reaching the interface of $\mathrm{HfO}_{2} / \mathrm{Si}_{0.7} \mathrm{Ge}_{0.3}$ decreases and the thickness of IL in the post-O sample also decreases. To further reduce the $\mathrm{D}_{\text {it }}$ of the $\mathrm{HfO}_{2} / \mathrm{Si}_{0.7} \mathrm{Ge}_{0.3}$ interface, a Si-cap passivation with the optimal thickness of $1 \mathrm{~nm}$ is developed and an excellent $\mathrm{HfO}_{2} / \mathrm{Si}_{0.7} \mathrm{Ge}_{0.3}$ interface with $\mathrm{D}_{\text {it }}$ of $1.53 \times 10^{11} \mathrm{eV}^{-1} \mathrm{~cm}^{-2} @ \mathrm{E}-\mathrm{E}_{\mathrm{v}}=0.36 \mathrm{eV}$ is attained. After detailed analysis of the chemical structure of the $\mathrm{HfO}_{2} / \mathrm{IL} / \mathrm{Si}$-cap $/ \mathrm{Si}_{0.7} \mathrm{Ge}_{0.3}$ using $\mathrm{X}$-ray photoelectron spectroscopy (XPS), it is confirmed that the excellent $\mathrm{HfO}_{2} / \mathrm{Si}_{0.7} \mathrm{Ge}_{0.3}$ interface is realized by preventing the formation of Hf-silicate/Hf-germanate and Si oxide originating from the reaction between $\mathrm{HfO}_{2}$ and $\mathrm{Si}_{0.7} \mathrm{Ge}_{0.3}$ substrate.
\end{abstract}

Keywords: $\mathrm{HfO}_{2} / \mathrm{Si}_{0.7} \mathrm{Ge}_{0.3}$ gate stack; ozone oxidation; Si-cap; interface state density; passivation

\section{Introduction}

High-mobility channel materials and novel device architectures, such as FinFETs (Fin Field-Effect Transistor) and nanowire FETs, are proposed to address the demand for scaling CMOS (Complementary Metal-Oxide-Semiconductor) technology [1,2]. In contrast to other potential materials, such as germanium (Ge) or III-V materials, silicon germanium (SiGe) is considered the most promising channel material for PMOS due to its tunability of band gaps and high hole mobility [3]. However, one of the main challenges in integrating SiGe into the novel devices is obtaining a high-quality interlayer (IL) between high-k gate oxide and SiGe substrate.

To control the interface quality, many methods have been extensively explored, such as plasma $\left(\mathrm{N}_{2}\right.$ or $\left.\mathrm{NH}_{3}\right)$ nitridation passivation [4,5], sulfur passivation [6], thermal oxidation [7,8], low-temperature ozone passivation [9-12] and Si-cap passivation [13]. Among them, low-temperature ozone passivation with low thermal budge and Si-cap passivation with excellent properties of interface are considered the most promising passivation methods. For example, the interface state density $\left(D_{i t}\right)$ of $2.2 \times 10^{12} \mathrm{eV}^{-1} \mathrm{~cm}^{-2}$ 
is attained by using a low-temperature ozone oxidation to passivate the interface of $\mathrm{Al}_{2} \mathrm{O}_{3} / \mathrm{Si}_{0.7} \mathrm{Ge}_{0.3}[11]$, and the $\mathrm{D}_{\text {it }}$ of $2 \times 10^{11} \mathrm{eV}^{-1} \mathrm{~cm}^{-2}$ for the interface of $\mathrm{HfO}_{2} / \mathrm{Si}_{0.8} / \mathrm{Ge}_{0.2}$ is realized by using a Si-cap passivation method [14]. However, the technique and mechanism of interface passivation of the $\mathrm{HfO}_{2} / \mathrm{SiGe}$ via low-temperature ozone oxidation or Si-cap method still needs further investigation.

In this paper, we fabricated $\mathrm{HfO}_{2} / \mathrm{IL} / \mathrm{Si}_{0.7} \mathrm{Ge}_{0.3}$ gate stacks $\mathrm{MOS}$ capacitors by utilizing low-temperature ozone oxidation and $\mathrm{Si}$ cap passivation methods. We carefully compared their electrical properties, and the chemical structure of $\mathrm{HfO}_{2} / \mathrm{IL} / \mathrm{SiGe}$ gate stacks. It is found that the post- $\mathrm{HfO}_{2}$-depositon (post-O) ozone indirect oxidation is a better choice than a step-by-step procedure (pre-O) method in terms of $\mathrm{D}_{\text {it }}$ reduction. More importantly, the optimal Si cap method can realize a lower $\mathrm{D}_{\mathrm{it}}$ of $1.53 \times 10^{11} \mathrm{eV}^{-1} \mathrm{~cm}^{-2} @ \mathrm{E}-\mathrm{E}_{\mathrm{v}}=0.36 \mathrm{eV}$ by preventing the formation of $\mathrm{Hf}$-silicate/Hf-germanate and $\mathrm{Si}$ oxide originating from the reaction between $\mathrm{HfO}_{2}$ and $\mathrm{Si}_{0.7} \mathrm{Ge}_{0.3}$ substrate.

\section{Materials and Methods}

After standard HF-last cleaning, the $30 \mathrm{~nm} \mathrm{Si}_{0.7} \mathrm{Ge}_{0.3}$ layer was epitaxially grown in a reduced pressure chemical vapor deposition system (ASM E2000 plus, Amsterdam, The Netherlands) on an 8-inch Si substrate. The low-temperature ozone passivation or Si-cap passivation was employed to passivate the interface of $\mathrm{HfO}_{2} / \mathrm{Si}_{0.7} \mathrm{Ge}_{0.3}$. For lowtemperature ozone passivation samples, the ozone oxidation can occur on the $\mathrm{Si}_{0.7} \mathrm{Ge}_{0.3}$ surface directly (step-by-step procedure (pre-O)) or post $\mathrm{HfO}_{2}$ deposition (post-O). The ozone oxidation was carried out in $10 \% \mathrm{O}_{3} / \mathrm{O}_{2}$ mixture ambience with the pressure of 3.1 Torr in an atomic-layer-deposition (ALD) chamber (Beneq TFS 200 system, Espoo, Finland). The temperature of the ozone oxidation was $300^{\circ} \mathrm{C}$. For Si-cap passivation, a Si-cap layer was in situ formed on the epitaxial $\mathrm{Si}_{0.7} \mathrm{Ge}_{0.3}$ layer in the same chamber. After the passivation treatment, the $\mathrm{W} / \mathrm{TiN}$ or $\mathrm{W} / \mathrm{TiN} / \mathrm{HfO}_{2}$ gate stack was deposited as the gate stack of MOS capacitors. Finally, W/TiN/ $\mathrm{HfO}_{2} / \mathrm{IL} / \mathrm{Si}_{0.7} \mathrm{Ge}_{0.3} \mathrm{MOS}$ capacitors were annealed in the forming gas $\left(10 \% \mathrm{H}_{2}, 90 \% \mathrm{~N}_{2}\right)$ at $350{ }^{\circ} \mathrm{C}$ for $30 \mathrm{~min}$.

The chemical structures of the $\mathrm{HfO}_{2} / \mathrm{IL} / \mathrm{Si}_{0.7} \mathrm{Ge}_{0.3}$ stacks were studied by X-ray photoelectron spectroscopy (XPS), which was carried out in a Thermo Scientific ESCALAB 250xi (Waltham, MA, USA) system with a photon energy of $1486.7 \mathrm{eV}$ (Al K $\alpha$ source). The photoelectron emission take-off angle was $90^{\circ}$ relative to the sample surface and the pass energy was $15 \mathrm{eV}$. Moreover, TEM (Transmission Electron Microscope) and EDX (Energy Dispersive X-Ray Spectroscopy) Mapping analysis were performed by using FEI Talos F200X (Hillsboro, MI, USA) to verify the gate stack lattice structure and element content. Multi-frequency capacitance-voltage (C-V) along with conductance-voltage (G-V) measurements were measured using a Keysight 4990 A (Santa Rosa, CA, USA), and leakage-voltage (I-V) was measured using an Agilent B-1500 semiconductor analyzer.

\section{Results and Discussion}

\subsection{Low-Temperature Ozone Oxidation Passivation of $\mathrm{HfO}_{2} / \mathrm{Si}_{0.7} \mathrm{Ge}_{0.3}$ Interface}

In our previous work, the low-temperature ozone oxidation passivation method has been studied in detail based on $\mathrm{Al}_{2} \mathrm{O}_{3} / \mathrm{Si}_{0.7} \mathrm{Ge}_{0.3}$ gate stacks. It was found that oxidation time played an important role to obtain a high-quality interlayer (IL) and should be at least 5 minutes. Otherwise, the unoxidized Ge atoms would be trapped in the IL, causing the IL as well as the relevant electrical properties to deteriorate. Moreover, increasing oxidation time would result in an increase in the ratio of $\mathrm{Si}^{4+}$ to $\mathrm{Si}^{3+}$ of the oxide interlayer, which can help decrease the $D_{i t}$ [15]. Thus, we chose $30 \mathrm{~min}$ as the oxidation time, which has proven to be an optimal experimental condition, to passivate the $\mathrm{HfO}_{2} / \mathrm{Si}_{0.7} \mathrm{Ge}_{0.3}$ interface in this work.

Figure $1 \mathrm{a}, \mathrm{b}$ depicts the multi-frequency $(1 \mathrm{kHz}$ to $1 \mathrm{MHz}) \mathrm{C}-\mathrm{V}$ characteristics of $\mathrm{W} / \mathrm{TiN} / \mathrm{Al}_{2} \mathrm{O}_{3} / \mathrm{IL} / \mathrm{Si}_{0.7} \mathrm{Ge}_{0.3}\left(\mathrm{Al}_{2} \mathrm{O}_{3}\right.$ sample) and $\mathrm{W} / \mathrm{TiN} / \mathrm{HfO}_{2} / \mathrm{IL} / \mathrm{Si}_{0.7} \mathrm{Ge}_{0.3}\left(\mathrm{HfO}_{2}\right.$-preO sample) MOS capacitors treated with 30 min ozone direct oxidation, respectively. The flat band voltages $\left(\mathrm{V}_{\mathrm{fb}}\right)$ are also shown in the figures. The frequency dispersion features 
of the $\mathrm{C}-\mathrm{V}$ curves observed at gate biases smaller than the $\mathrm{V}_{\mathrm{fb}}$, are caused by trapping and de-trapping of holes at traps with energies between approximately mid-gap and the $\mathrm{Si}_{0.7} \mathrm{Ge}_{0.3}$ valence band edge, corresponding to the depletion of the $\mathrm{Si}_{0.7} \mathrm{Ge}_{0.3}$ substrate. Comparing Figure $1 \mathrm{~b}$ with Figure $1 \mathrm{a}$, it is observed that the dispersion feature increases considerably. The energy distributions of the interface state density $\left(D_{i t}\right)$ were extracted using the conductance method [16], and given in their respective inset in Figure 1. We can see that both of the $D_{i t}$ of the two samples decreases along with SiGe band gap energy and the maximum $D_{i t}$ values appear near the valence band edge $\left(E_{\mathrm{v}}\right)$. However, the maximum value increases from $3.96 \times 10^{12} \mathrm{eV}^{-1} \mathrm{~cm}^{-2}$ for the $\mathrm{Al}_{2} \mathrm{O}_{3}$ sample to $2.67 \times 10^{13} \mathrm{eV}^{-1} \mathrm{~cm}^{-2}$ for the $\mathrm{HfO}_{2}$-pre-O sample. According to our previous work [17], it is known that for $300{ }^{\circ} \mathrm{C} / 30 \mathrm{~min}$ ozone oxidation, about $54 \%$ of the Ge atoms of the outermost atomic layer of $\mathrm{Si}_{0.7} \mathrm{Ge}_{0.3}$ can be oxidized in the initial stage of oxidation. No more Ge atoms would take part in the oxidation process as the oxidation time increases. The $\mathrm{GeO}_{x}$ and $\mathrm{SiO}_{\mathrm{x}}$ thickness of the formed oxide layer are estimated to be $0.15 \mathrm{~nm}$ and $0.72 \mathrm{~nm}$, respectively. Compared with $\mathrm{Al}_{2} \mathrm{O}_{3}, \mathrm{GeO}_{\mathrm{x}}$ is more likely to diffuse into $\mathrm{HfO}_{2}$ and cause the $\mathrm{HfO}_{2} / \mathrm{SiGe}$ interface to deteriorate [18]. Therefore, the increased $\mathrm{D}_{\mathrm{it}}$ of the $\mathrm{HfO}_{2}$-pre-O sample can be attributed to tiny amounts of $\mathrm{GeO}_{\mathrm{x}}$ in the formed oxide layer.
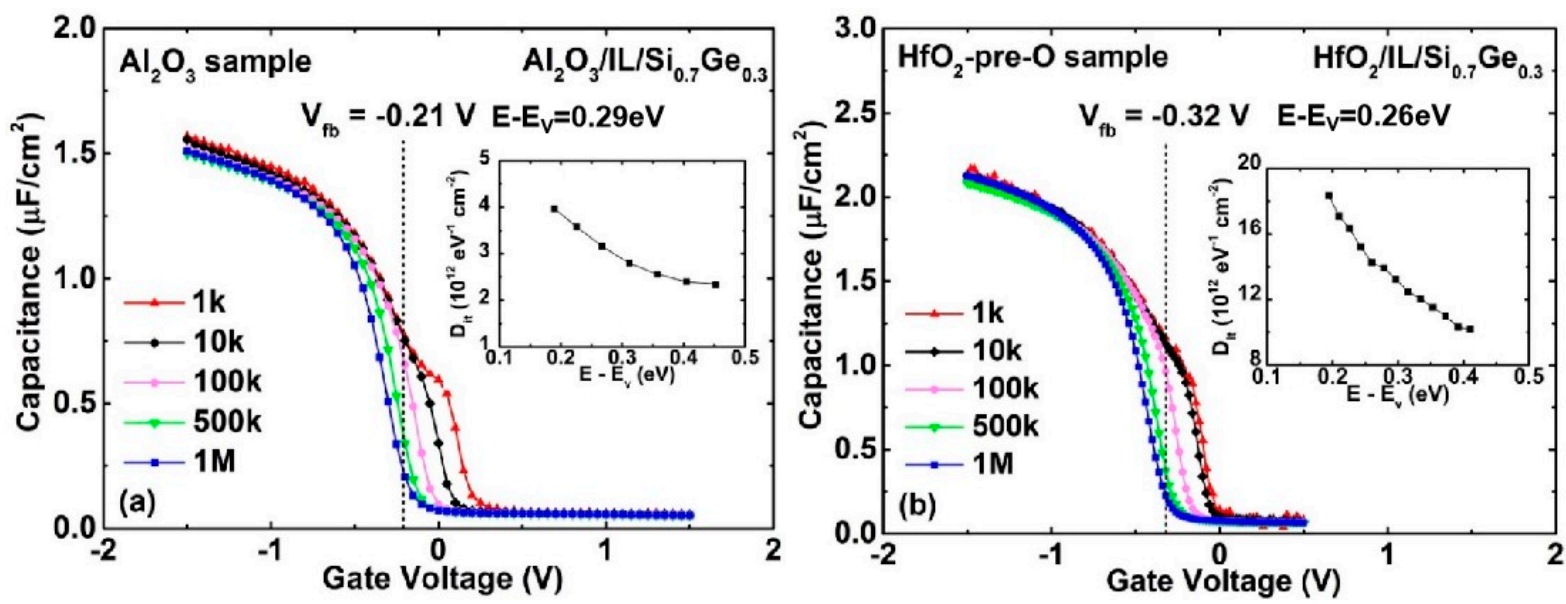

Figure 1. Multi-frequency $\mathrm{C}-\mathrm{V}$ characteristics of (a) $\mathrm{Al}_{2} \mathrm{O}_{3}$ sample (b) $\mathrm{HfO}_{2}$-pre-O sample with 30 min oxidation time (direct). The insets are their respective energy distributions of $\mathrm{D}_{\mathrm{it}}$.

Figure 2 depicts the multi-frequency $(1 \mathrm{kHz}$ to $1 \mathrm{MHz}) \mathrm{C}-\mathrm{V}$ characteristics of W/TiN/ $\mathrm{HfO}_{2} / \mathrm{IL} / \mathrm{Si}_{0.7} \mathrm{Ge}_{0.3}\left(\mathrm{HfO}_{2}\right.$-post-O sample) MOS capacitor treated with 30 min ozone indirect oxidation, in which the ozone oxidation was carried out after the deposition of $\mathrm{HfO}_{2}$. The corresponding energy distributions of $D_{i t}$ is also given in the inset. Compared with Figure $1 \mathrm{~b}$, an obvious improvement in the frequency dispersion feature is observed, and the $\mathrm{D}_{\text {it }}$ value decreases by about $50 \%$. We infer that the improvement may arise from the following two factors. First, due to the barrier effect of the $\mathrm{HfO}_{2}$ layer on the diffusion of the oxidizer, the amount of oxygen atoms reaching the interface becomes fewer. Because silicon oxidation is more favorable than germanium oxidation in view of thermodynamic considerations [19], germanium atoms are hardly oxidized in this case. Therefore, almost no $\mathrm{GeO}_{x}$ would diffuse into $\mathrm{HfO}_{2}$ layer. In addition, the IL thickness of the $\mathrm{HfO}_{2}$-post-O sample is smaller than that of the $\mathrm{HfO}_{2}$-pre-O sample, which means the amounts of the Ge atoms accumulating at the IL/SiGe interface decrease accordingly. The experimental results prove that the post-O method is a promising technology to realize an $\mathrm{HfO}_{2} / \mathrm{IL} / \mathrm{SiGe}$ gate stack with small $\mathrm{D}_{\mathrm{it}}$. 


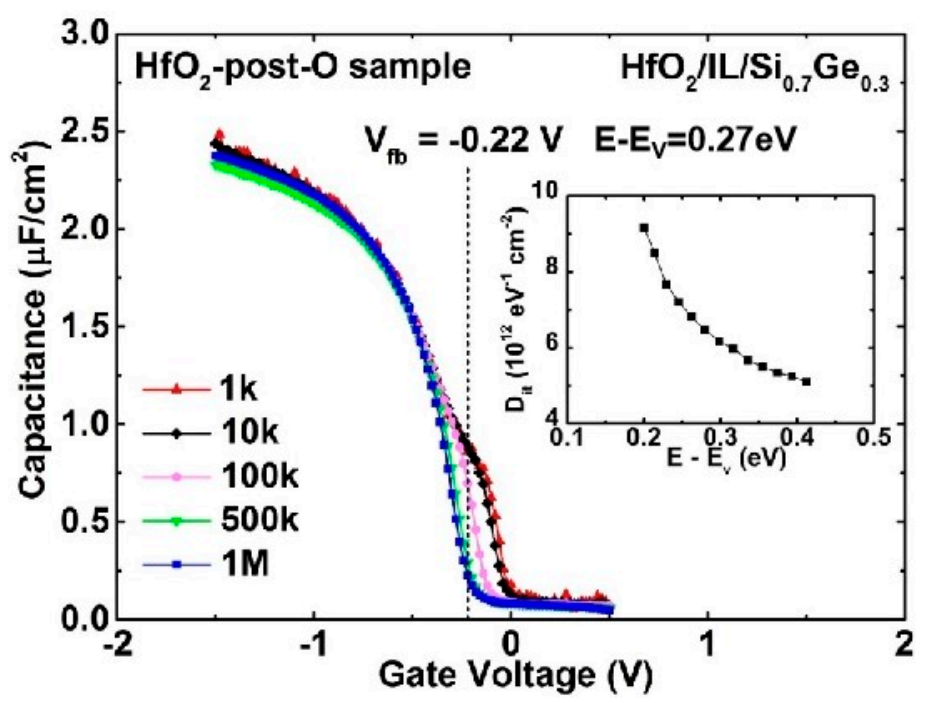

Figure 2. Multi-frequency $\mathrm{C}-\mathrm{V}$ characteristics of $\mathrm{HfO}_{2}$-post-O sample with 30 min oxidation time (indirect). The corresponding energy distributions of $\mathrm{D}_{\mathrm{it}}$ is given in the inset.

The $\mathrm{Al}_{2} \mathrm{O}_{3}$ sample, $\mathrm{HfO}_{2}$-pre-O sample and $\mathrm{HfO}_{2}$-post-O sample were compared on capacitance equivalent oxide thickness (CET) at $-1.5 \mathrm{~V}$ bias voltage in accumulation. The CETs of each are $2.28 \mathrm{~nm}, 1.5 \mathrm{~nm}$ and $1.37 \mathrm{~nm}$ respectively. Comparing the $\mathrm{Al}_{2} \mathrm{O}_{3}$ sample with the $\mathrm{HfO}_{2}$, the CET of the $\mathrm{Al}_{2} \mathrm{O}_{3}$ sample is bigger. The $\mathrm{HfO}_{2}$-post-O sample decreased the CET, compared to the $\mathrm{HfO}_{2}$-pre-O sample. This is supposed to be related to the diffusion of $\mathrm{GeO}_{x}$. In general, the diffusion of $\mathrm{GeO}_{\mathrm{x}}$ is less in $\mathrm{Al}_{2} \mathrm{O}_{3}$ and $\mathrm{HfO}_{2}$-post-O. Using the post-O method can limit the diffusion of $\mathrm{GeO}_{\mathrm{x}}$ in $\mathrm{HfO}_{2}$. The diffusion of $\mathrm{GeO}_{\mathrm{x}}$ affects not only the CET but also the leakage current.

Figure 3 shows the gate Leakage of the $\mathrm{Al}_{2} \mathrm{O}_{3}$ sample, $\mathrm{HfO}_{2}$-pre-O sample and $\mathrm{HfO}_{2}-$ post-O sample. Because $\mathrm{GeO}_{x}$ is not easily diffused in $\mathrm{Al}_{2} \mathrm{O}_{3}$, the leakage current is minimal for the $\mathrm{Al}_{2} \mathrm{O}_{3}$ sample. Comparing with the $\mathrm{HfO}_{2}$-pre-O sample, the leakage current $\mathrm{HfO}_{2}-$ post-O sample can be reduced by an order of magnitude.

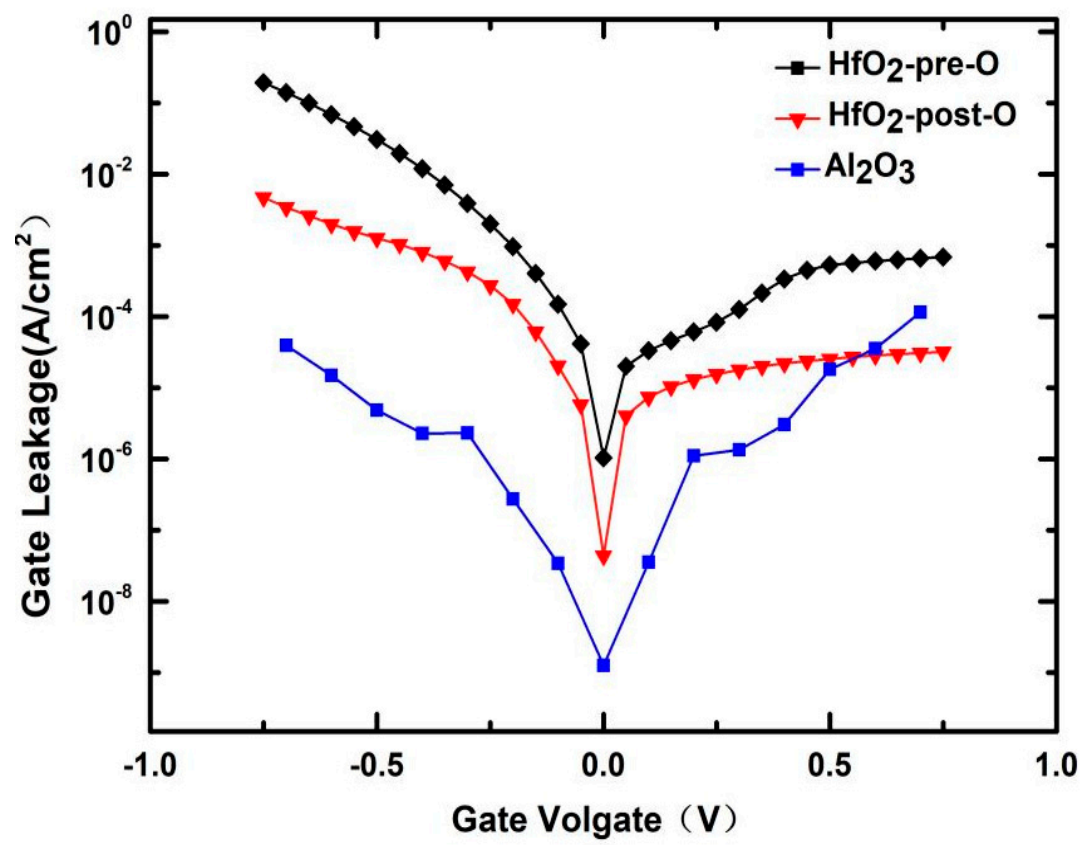

Figure 3. Gate leakage of $\mathrm{Al}_{2} \mathrm{O}_{3}$ sample, $\mathrm{HfO}_{2}$-pre-O sample and $\mathrm{HfO}_{2}$-post-O sample. 


\subsection{Si-Cap Passivation of $\mathrm{HfO}_{2} / \mathrm{Si}_{0.7} \mathrm{Ge}_{0.3}$ Interface}

To further reduce the $\mathrm{D}_{\mathrm{it}}$ of the $\mathrm{HfO}_{2} / \mathrm{Si}_{0.7} \mathrm{Ge}_{0.3}$ interface, Si-cap passivation is in situ performed on the $\mathrm{Si}_{0.7} \mathrm{Ge}_{0.3}$ layer with different thicknesses. It is found that if the $\mathrm{Si}$ cap thickness is larger than or equal to $2 \mathrm{~nm}$, there is a step observed in its C-V curve because a second channel is formed in the $\mathrm{Si}$ cap layer. This can be avoided by further thinning of the Si cap layer to $1 \mathrm{~nm}$. Moreover, multi-frequency $\mathrm{C}-\mathrm{V}$ curves $(1 \mathrm{kHz}$ to $1 \mathrm{MHz}$ ) of the $\mathrm{W} / \mathrm{TiN} / \mathrm{HfO}_{2} / \mathrm{IL} / \mathrm{Si}$-cap $/ \mathrm{Si}_{0.7} \mathrm{Ge}_{0.3} \mathrm{MOS}$ capacitor with $1 \mathrm{~nm}$ Si-cap are measured and shown in Figure 3. It is worthy to note that the frequency dispersive feature is obviously improved compared with the above ozone passivation. However, the CET of the Si-cap sample from Figure 4 may be inaccurate due to the large gate leakage in the accumulation region. In addition, it can be seen that the carriers are mainly confined in the $\mathrm{Si}_{0.7} \mathrm{Ge}_{0.3}$ layer under this optimal Si-cap thickness due to its large valance band offset. For quantitative analysis, the $D_{i t}$ of $1.53 \times 10^{11} \mathrm{eV}^{-1} \mathrm{~cm}^{-2} @ \mathrm{E}-\mathrm{E}_{\mathrm{v}}=0.36 \mathrm{eV}$ is attained by using the conductance method. Meanwhile, HRTEM, Si and Ge element EDX mapping of the $\mathrm{W} / \mathrm{TiN} / \mathrm{HfO}_{2} / \mathrm{IL} / \mathrm{Si}$-cap $/ \mathrm{Si}_{0.7} \mathrm{Ge}_{0.3} \mathrm{MOS}$ capacitor with $1 \mathrm{~nm} \mathrm{Si}$-cap is also implemented and shown in Figure 5. It is found that there is a $\sim 0.6 \mathrm{~nm} \mathrm{Si} \mathrm{capping}$ on the $\mathrm{Si}_{0.7} \mathrm{Ge}_{0.3}$ with a smooth and high-quality interfacial layer. The reduction of $\mathrm{Si}$ cap thickness of $0.4 \mathrm{~nm}$ is due to the oxidation of $\mathrm{Si}$ cap layer in the process of MOS capacitor fabrication. Therefore, 1-nm Si-cap in situ epitaxial grown is chosen as the optimal Si-cap thickness.

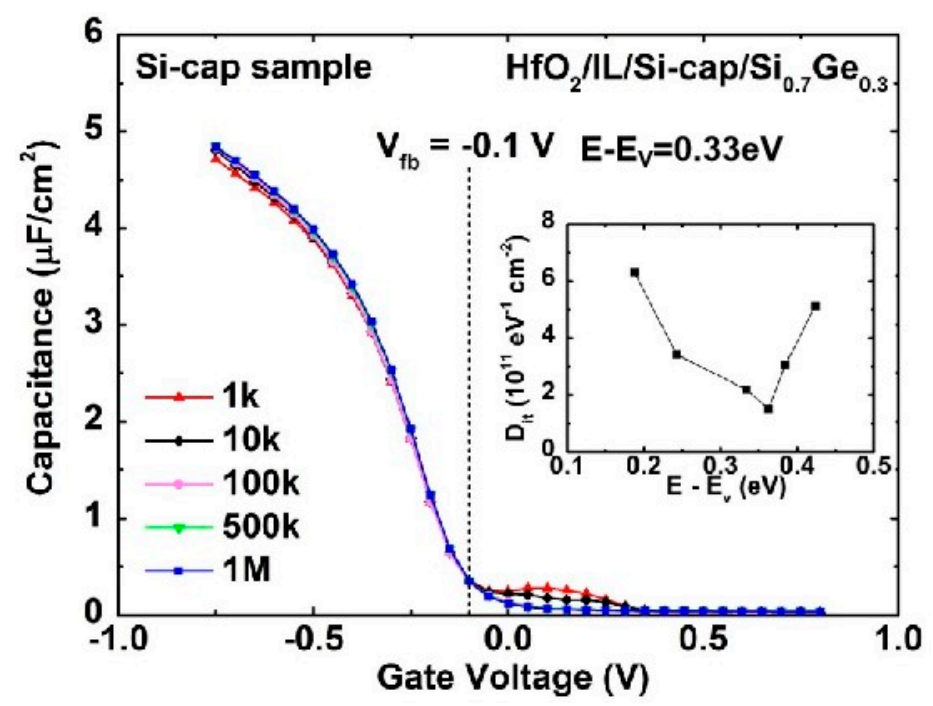

Figure 4. Multi-frequency $\mathrm{C}-\mathrm{V}$ characteristic of $\mathrm{W} / \mathrm{TiN} / \mathrm{HfO}_{2} / \mathrm{IL} / \mathrm{Si}$-cap $/ \mathrm{Si}_{0.7} \mathrm{Ge}_{0.3} \mathrm{MOS}$ capacitor with $1 \mathrm{~nm}$ Si-cap.
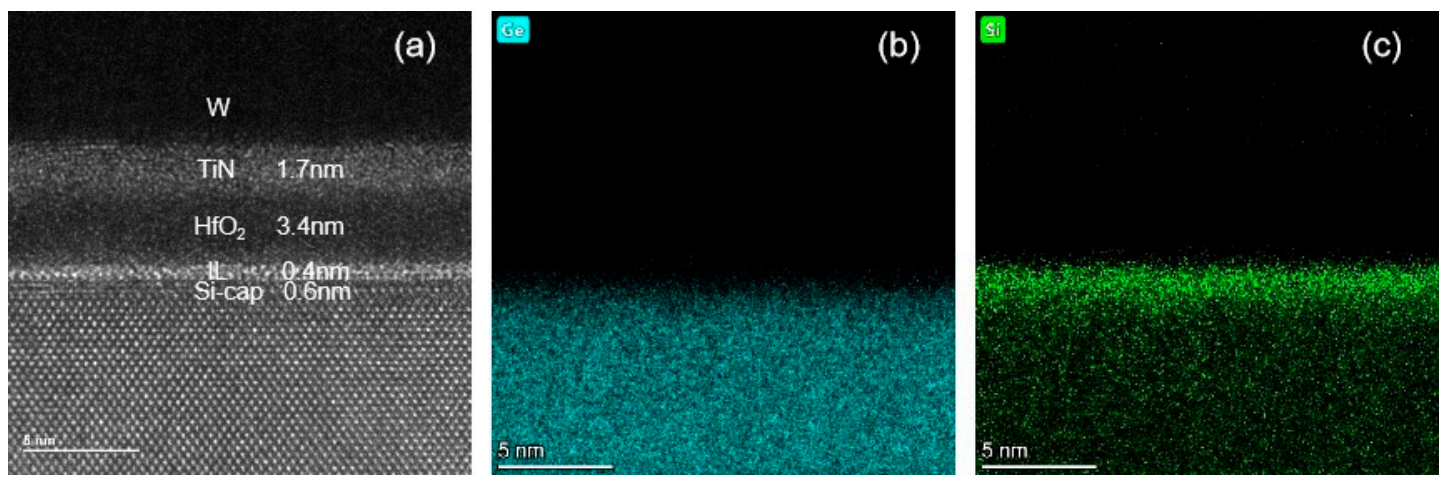

Figure 5. (a) HRTEM, (b) Ge, and (c) Si element EDX mapping of the W/TiN/HfO $/$ IL/Si-cap $/ \mathrm{Si}_{0.7} \mathrm{Ge}_{0.3} \mathrm{MOS}$ capacitor with $1 \mathrm{~nm}$ Si-cap. 
For the purpose of investigating the chemical structure of the $\mathrm{HfO}_{2} / \mathrm{IL} / \mathrm{Si}$-cap $/ \mathrm{Si}_{0.7} \mathrm{Ge}_{0.3}$ gate stack (Si-cap sample), X-ray photoelectron spectroscopy (XPS) technology is implemented. The chemical structure of the $\mathrm{HfO}_{2} / \mathrm{Si}_{0.7} \mathrm{Ge}_{0.3}$ gate stack ( $\mathrm{SiGe}$ sample), in which $\mathrm{HfO}_{2}$ is deposited on $\mathrm{Si}_{0.7} \mathrm{Ge}_{0.3}$ directly, is also analyzed as a control sample. GaussianLorentzian line shapes are used for deconvolution of all the spectra after standard Shirley background subtraction [20]. Figure 6a,b shows the Hf $4 \mathrm{f}$ core-level spectra of the Si-cap sample and SiGe sample, respectively. The spectra are both fitted with two component peaks. For the Si-cap sample (shown in Figure 6a), the Hf $4 \mathrm{f}$ spectrum consists of a main component at $16.8 \mathrm{eV}$ related to the $\mathrm{Hf}-\mathrm{O}$ bands in $\mathrm{HfO}_{2}$, and a second component shifted by $\sim 0.9 \mathrm{eV}$ to higher binding energy, which is from the Hf-O-Si and/or Hf-O-Ge bonds. Because the electro-negativities of the Hf second neighbors (i.e., Si and $\mathrm{Ge}$ ) are similar, it is difficult to distinguish the two contributions of Hf-O-Si and Hf-O-Ge bonds by XPS. It is worth noting that for the SiGe sample (shown in Figure 6b), the areal intensity of $\mathrm{Hf}-\mathrm{O}-\mathrm{Si}$ /Hf-O-Ge is much more than that of Hf-O. This suggests that a large portion of $\mathrm{HfO}_{2}$ would react with SiGe to form Hf-silicate/Hf-germanate during the $\mathrm{HfO}_{2}$ ALD deposition process. In addition, no feature of lower banding energy $(14.3 \mathrm{eV}-14.8 \mathrm{eV})$ is detected, indicating that no metallic Hf-Si and/or Hf-Ge are formed in the two samples.
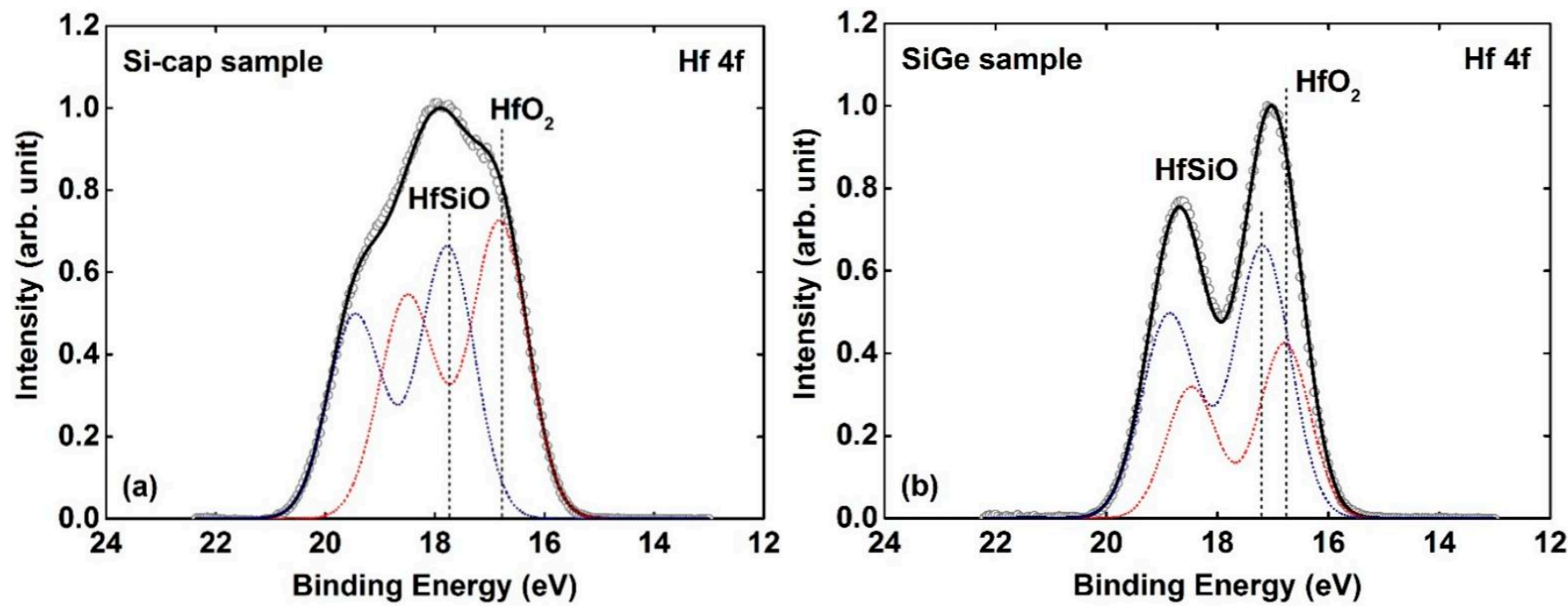

Figure 6. The fitted Hf $4 \mathrm{f}$ core-level spectra of (a) Si-cap sample and (b) SiGe sample. The blue and red dot lines denote the $\mathrm{Hf} 4 \mathrm{f}$ photoelectron from Hf-O-Si and/or Hf-O-Ge bonds and $\mathrm{Hf}-\mathrm{O}$ bonds in $\mathrm{HfO}_{2}$, respectively.

Figure 7a,b shows the Si 2p core-level spectra of the Si-cap sample and the SiGe sample, respectively. The spectra are decomposed into four component peaks i.e., $\mathrm{Si}$ 2p photoelectron from SiGe ( 99.7 eV), $\mathrm{SiO}_{\mathrm{x}}(\sim 101.2 \mathrm{eV}), \mathrm{HfSiO}(\sim 102.8 \mathrm{eV})$, and $\mathrm{SiO}_{2}$ $(\sim 103.9 \mathrm{eV})$. For the Si-cap sample (shown in Figure $7 \mathrm{a})$, the high-binding energy shoulder $(101 \mathrm{eV} \sim 105 \mathrm{eV})$ contains few amounts of $\mathrm{Si}$ oxide $\left(\mathrm{SiO}_{\mathrm{x}}\right.$ and $\left.\mathrm{SiO}_{2}\right)$ and $\mathrm{Hf}$-silicate (HfSiO). When compared with the Si-cap sample, an obvious increase in the areal intensity of the high-binding energy shoulder $(101 \mathrm{eV} 105 \mathrm{eV})$ can be observed for the SiGe sample, and there is no peak corresponding $\mathrm{SiO}_{\mathrm{x}}$. Figure $8 \mathrm{a}$,b shows the $\mathrm{O}$ 1s core-level spectra of the SiGe sample and Si-cap sample, respectively. The spectra are fitted by the $\mathrm{O} 1 \mathrm{~s}$ of $\mathrm{SiO}_{\mathrm{x}}$ $(\sim 532.8 \mathrm{eV}), \mathrm{HfSiO}(\sim 532.08 \mathrm{eV})$ and $\mathrm{HfO}_{2}(\sim 531 \mathrm{eV})$. We can see that the $\mathrm{O} 1$ s photoelectron mainly originates from $\mathrm{HfO}_{2}$ for the Si-cap sample, while that of the SiGe sample is mainly from $\mathrm{SiO}_{\mathrm{x}}$ and $\mathrm{HfSiO}$. This is consistent with the previous discussions about $\mathrm{Hf} 4 \mathrm{f}$ and $\mathrm{Si}$ $2 p$ spectra. All of these results indicate that the interfacial region of the $\mathrm{HfO}_{2} / \mathrm{SiGe}(\mathrm{SiGe}$ sample) is a composite of large amounts of $\mathrm{HfSiO}$ (and/or $\mathrm{HfGeO}$ ) and $\mathrm{Si}$ oxide $\left(\mathrm{SiO}_{2}\right)$. In other words, Si-cap can prevent the formation of Hf-silicate/Hf-germanate and Si oxide originating from the reaction between $\mathrm{HfO}_{2}$ and $\mathrm{SiGe}$ substrate, and obtain an excellent $\mathrm{HfO}_{2} / \mathrm{SiGe}$ interface. 

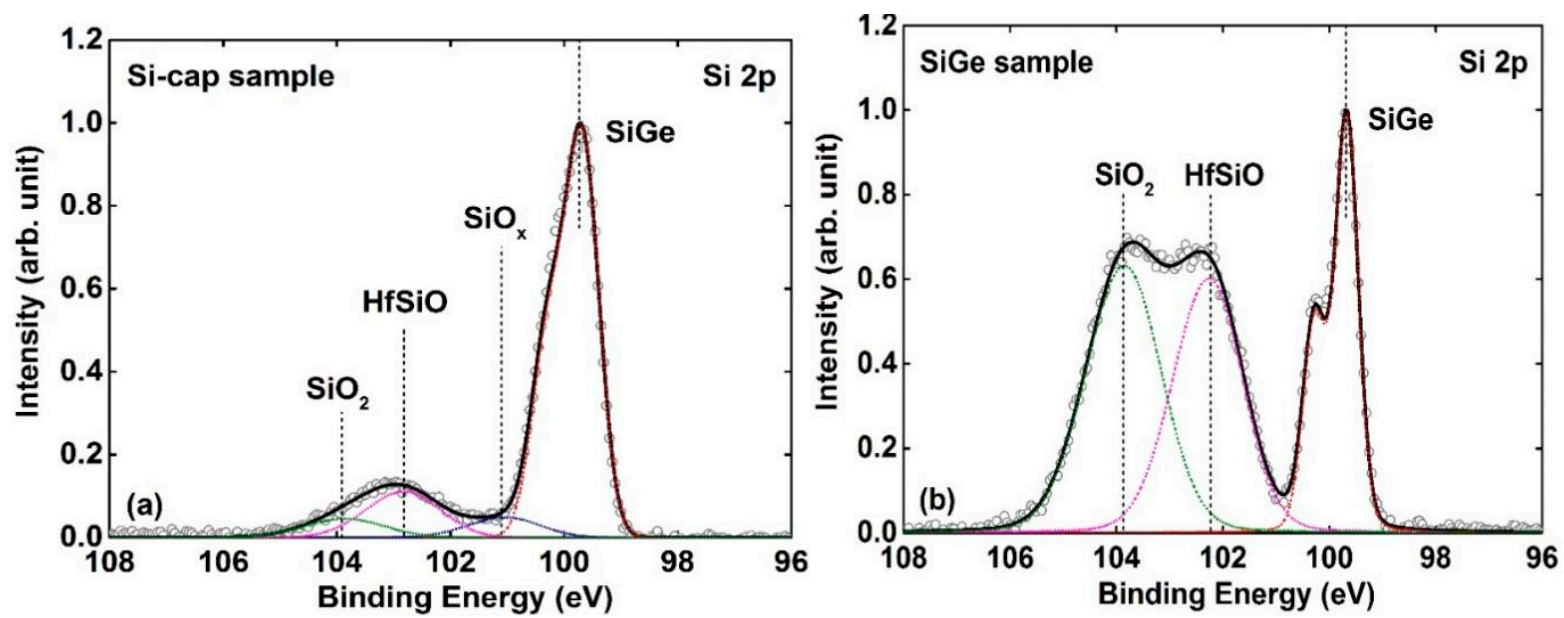

Figure 7. The fitted Si $2 p$ core-level spectra of (a) Si-cap sample (b) SiGe sample. The red, blue, magenta, and green dot lines denote the $\mathrm{Si} 2 \mathrm{p}$ of $\mathrm{SiGe}, \mathrm{SiO}_{x}, \mathrm{HfSiO}$, and $\mathrm{SiO}_{2}$, respectively.
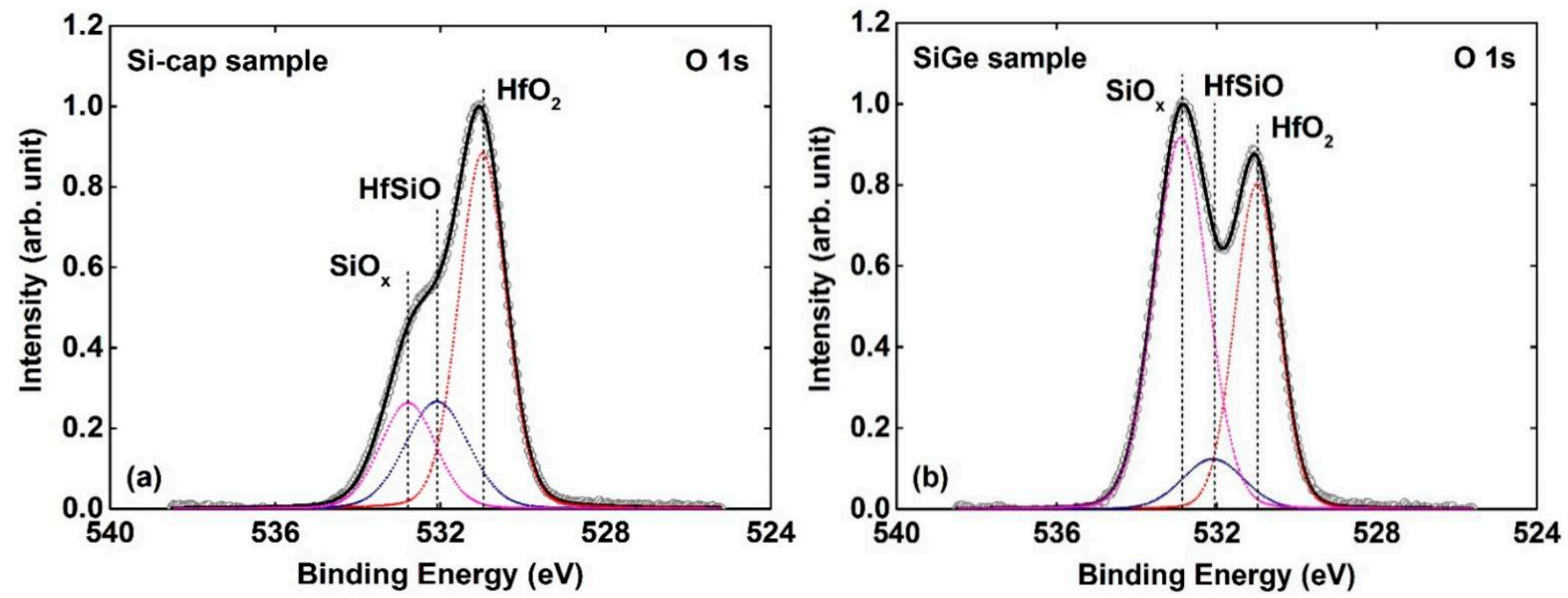

Figure 8. The fitted O 1s core-level spectra of (a) Si-cap sample (b) SiGe sample. The red, blue, and magenta dot lines denote the $\mathrm{O} 1 \mathrm{~s}$ photoelectron from $\mathrm{HfO}_{2}, \mathrm{HfSiO}$, and $\mathrm{SiO}_{x}$, respectively.

\section{Conclusions}

In summary, the interface passivation of the $\mathrm{HfO}_{2} / \mathrm{Si}_{0.7} \mathrm{Ge}_{0.3}$ stack is systematically investigated based on low-temperature ozone oxidation and Si-cap methods. Compared with pre-O method, the $\mathrm{D}_{\text {it }}$ of the post-O sample decreases by about $50 \%$ due to less $\mathrm{GeO}_{x}$ available in the IL layer. However, the $\mathrm{D}_{\mathrm{it}}$ of the $\mathrm{HfO}_{2} / \mathrm{IL} / \mathrm{Si}_{0.7} \mathrm{Ge}_{0.3}$ gate stack still has room to be further optimized. Finally, an excellent $\mathrm{HfO}_{2} / \mathrm{Si}_{0.7} \mathrm{Ge}_{0.3}$ interface with a $\mathrm{D}_{\text {it }}$ of $1.53 \times 10^{11} \mathrm{eV}^{-1} \mathrm{~cm}^{-2} @ \mathrm{E}-\mathrm{E}_{\mathrm{v}}=0.36 \mathrm{eV}$ is attained under the optimal Si cap method by preventing the formation of Hf-silicate/Hf-germanate and $\mathrm{Si}$ oxide from the reaction $\mathrm{HfO}_{2}$ and $\mathrm{Si}_{0.7} \mathrm{Ge}_{0.3}$ substrate.

Author Contributions: Conceptualization, X.M., Y.W. and Y.L.; methodology, Q.Y., X.M., H.W., Y.W., G.W., J.Z., W.L., X.W., J.Y., Y.L. and W.W.; investigation, Q.Y., X.M., Y.W. and Y.L., data curation, Q.Y., X.M., H.W., Y.W. and Y.L.; writing original draft preparation, Q.Y., X.M., Y.W. and Y.L.; writing review and editing, X.M., Y.W., Y.L. and J.Z.; supervision, J.Y., Y.L. and W.W.; project administration, Y.L. and W.W.; funding acquisition, W.W. All authors have read and agreed to the published version of the manuscript. 
Funding: This research was funded in part by the Science and Technology Program of Beijing Municipal Science and Technology Commission (Grant no. Z201100004220001), in part by the CAS Pioneer Hundred Talents Program, in part by Beijing Municipal Natural Science Foundation (Grant no. 4202078), in part by National Natural Science Foundation of China (Grant no. 62074160) and in part by Scientific Research Startup Foundation of North China University of Technology.

Institutional Review Board Statement: Not applicable.

Informed Consent Statement: Not applicable.

Data Availability Statement: Not applicable.

Acknowledgments: We thank the Integrated Circuit Advanced Process Center (ICAC) at the Institute of Microelectronics of the Chinese Academy of Sciences for the devices fabricated on their advanced $200 \mathrm{~mm}$ CMOS platform.

Conflicts of Interest: The authors declare no conflict of interest.

\section{References}

1. Mertens, H.; Ritzenthaler, R.; Arimura, H.; Franco, J.; Sebaai, F.; Hikavyy, B.A.; Pawlak, J.; Machkaoutsan, V.; Devriendt, K.; Tsvetanova, D.; et al. Si-cap-free SiGe p-Channel FinFETsand Gate-All-Around Transistors in a Replacement Metal Gate Process: Interface Trap Density Reduction and Performance Improvement by High-Pressure Deuterium Anneal. In Proceedings of the 2015 Symposium on VLSI Technology, Kyoto, Japan, 16-18 June 2015.

2. Hashemi, P.; Balakrishnan, K.; Engelmann, S.U.; Ott, J.A.; Khakifirooz, A.; Baraskar, A.; Hopstaken, M.; Newbury, J.S.; Chan, K.K.; Leobandung, E.; et al. First Demonstration of High-Ge-Content Strained-Si1-xGex $(x=0.5)$ on Insulator PMOS FinFETs with High Hole Mobility and Aggressively ScaledFin Dimensions and Gate Lengths for High-Performance Applications. In Proceedings of the 2014 IEEE International Electron Devices Meeting, San Francisco, CA, USA, 15-17 December 2014.

3. Hashemi, P.; Ando, T.; Balakrishnan, K.; Bruley, J.; Engelmann, S.; Ott, J.A.; Narayanan, V.; Park, D.-G.; Mo, R.T.; and Leobandung, E. High-Mobility High-Ge-Content Si1-xGex-OI PMOS FinFETs with Fins Formed Using 3D Germanium Condensation with Ge Fraction up to $x \sim 0.7$, Scaled EOT $\sim 8.5 \AA$ and $\sim 10 \mathrm{~nm}$ Fin Width. In Proceedings of the 2015 Symposium on VLSI Circuits, Kyoto, Japan, 17-19 June 2015.

4. Han, J.; Zhang, R.; Osada, T.; Hata, M.; Takenaka, M.; Takagi, S. Impact of plasma post-nitridation on $\mathrm{HfO}_{2} / \mathrm{Al}_{2} \mathrm{O}_{3} / \mathrm{SiGe}_{\mathrm{Gate}}$ stacks toward EOT scaling. Microelectron. Eng. 2013, 109, 266-269. [CrossRef]

5. Sardashti, K.; Hu, K.-T.; Tang, K.; Madisetti, S.; McIntyre, P.; Oktyabrsky, S.; Siddiqui, S.; Sahu, B.; Yoshida, N.; Kachian, J.; et al. Nitride passivation of the interface between high-k dielectrics and SiGe. Appl. Phys. Lett. 2016, 108, 011604. [CrossRef]

6. Sardashtia, K.; Hua, K.T.; Tang, K.; Parka, S.; Kim, H.; Madisetti, S.; Oktyabrsky, S.; Siddiqui, S.; Sahu, B.; Yoshida, N.; et al. Sulfur passivation for the formation of Si-terminated $\mathrm{Al}_{2} \mathrm{O}_{3} / \mathrm{SiGe}\left(\begin{array}{ll}0 & 1\end{array}\right)$ interfaces. Appl. Surf. Sci. 2016, 366, 455-463. [CrossRef]

7. Hellberg, P.-E.; Zhang, S.-L.; d'Heurle, F.M.; Petersso, C.S. Oxidation of silicon-germanium alloys. I. An experimental study. J. Appl. Phys. 1997, 82, 5773-5778.

8. Masanori, T.; Tatsuo, O.; Taizoh, S.; Miyao, M. Comprehensive study of low temperature $\left(<1000^{\circ} \mathrm{C}\right)$ oxidation process in SiGe/SOI structures. Thin Solid Films 2008, 517, 251-253.

9. Song, Y.J.; Mheen, B.; Kang, J.Y.; Lee, Y.S.; Lee, N.E.; Kim, J.H.; Song, J.I.; Shim, K.-H. A low-temperature and high-quality radical-assisted oxidation process utilizing a remote ultraviolet ozone source for high-performance SiGe/Si MOSFETs. Semicond. Sci. Technol. 2004, 19, 792-797. [CrossRef]

10. Ando, T.; Hashemi, P.; Bruley, J.; Rozen, J.; Ogawa, Y.; Koswatta, S.; Chan, K.K.; Cartier, E.A.; Mo, R.; Narayanan, V. High Mobility High-Ge-Content SiGe PMOSFETs Using $\mathrm{Al}_{2} \mathrm{O}_{3} / \mathrm{HfO}_{2}$ Stacks with In-Situ $\mathrm{O}_{3}$ Treatment. IEEE Electron. Device Lett. 2017, 38 , 303-305. [CrossRef]

11. Ma, X.L.; Xiang, J.J.; Zhou, L.X.; Wang, X.L.; Li, Y.L.; Yang, H.; Zhang, J.; Zhao, C.; Yin, H.X.; Wang, W.W.; et al. Comprehensive Study and Design of High-k/SiGe Gate Stacks with Interface-Engineering by Ozone Oxidation. ECS J. Solid-State Sci. Technol 2019, 8, N100-N105. [CrossRef]

12. Ma, X.L.; Xiang, J.J.; Zhou, L.X.; Xu, H.; Wang, X.L.; Yang, H.; Li, Y.L.; Yin, H.X.; Wang, W.W. Understanding mechanisms impacting interface states of ozone-treated high-k/SiGe interfaces. Semicond. Sci. Technol. 2020, 35, 055018. [CrossRef]

13. Yeh, W.K.; Chen, Y.T.; Huang, F.S.; Hsu, C.W.; Chen, C.Y.; Fang, Y.K.; Gan, K.J.; Chen, P.Y. The Improvement of High-k/Metal Gate pMOSFET Performance and Reliability Using Optimized Si Cap/SiGe Channel Structure. IEEE Trans. Device Mater. Reliab. 2011, 11, 7-12. [CrossRef]

14. Tsutsui, G.; Durfee, C.; Wang, M.M.; Konar, A.; Wu, H.; Mochizuki, S.; Bao, R.Q.; Bedell, S.; Li, J.T.; Zhou, H.M.; et al. Leakage Aware Si/SiGe CMOS FinFET for Low Power Applications. In Proceedings of the 2008 IEEE Symposium on VLSI Technology, Honolulu, HI, USA, 18-22 June 2018.

15. Ma, X.L.; Zhou, L.X.; Xiang, J.J.; Yang, H.; Wang, X.L.; Li, Y.L.; Zhang, J.; Zhao, C.; Yin, H.X.; Wang, W.W.; et al. Identification of a suitable passivation route for high-k/SiGe interface based on ozone oxidation. Appl. Surf. Sci. 2019, 493, 478-484. [CrossRef] 
16. Nicollian, E.H.; Brews, J.R. MOS (Metal Oxide Semiconductor) Physicsand Technology; John Wiley \& Sons Inc.: Hoboken, NJ, USA, 1982; p. 176.

17. Ma, X.L.; Wang, X.L.; Zhou, L.X.; Xu, H.; Zhang, Y.Y.; Duan, J.H.; Xiang, J.J.; Yang, H.; Li, J.J.; Li, Y.L.; et al. Experimental study of the ultrathin oxides on SiGe alloy formed by low-temperature ozone oxidation. Mater. Sci. Semicond. Process. 2020, 107, 104832. [CrossRef]

18. Gusev, E.P.; Shang, H.; Copel, M.; Gribelyuk, M.; D’Emic, C.; Kozlowski, P.; Zabel, T.; Gusev, E.P.; Shang, H.; Copel, M.; et al. Microstructure and thermal stability of $\mathrm{HfO}_{2}$ gate dielectric deposited on $\mathrm{Ge}(100)$. Appl. Phys. Lett. 2004, 85, 2334. [CrossRef]

19. Chang, C.T.; Toriumi, A. Preferential Oxidation of Si in SiGe for Shaping Ge-Rich SiGe Gate Stacks. In Proceedings of the 2015 IEEE International Electron Devices Meeting (IEDM), Washington, DC, USA, 7-9 December 2015.

20. Shirley, D.A. High-Resolution X-ray Photoemission Spectrumof the Valence Bands of Gold. Phys. Review B 1972, 5, 4709. [CrossRef] 